\title{
REFLEXÃO E AÇÃO: A PEDAGOGIA HISTÓRICO-CRÍTICA E SUAS POSSIBILIDADES EM UM GRUPO DE ESTUDOS COM PROFESSORES DE LÍNGUA PORTUGUESA
}

\author{
REFLEXIÓN Y ACCIÓN: LA PEDAGOGÍA HISTÓRICO-CRÍTICA Y SUS \\ POSIBILIDADES EN UN GRUPO DE ESTUDIOS CON PROFESORES DE LENGUA \\ PORTUGUESA
}

\begin{abstract}
REFLECTION AND ACTION: A HISTORICAL-CRITICAL PEDAGOGY AND ITS POSSIBILITIES IN A STUDY GROUP WITH PORTUGUESE LANGUAGE TEACHERS
\end{abstract}

\author{
Geuciane Felipe Guerim FERNANDES ${ }^{1}$ \\ Sandra Aparecida Pires FRANCO ${ }^{2}$
}

RESUMO: Este artigo tem o objetivo de evidenciar um processo formativo realizado com professores de Língua Portuguesa à luz da Pedagogia Histórico-Crítica. Defende-se uma formação sólida que possibilite a apropriação do conhecimento em sua totalidade, a fim de superar o imediatismo e viabilizar a formação humana em suas múltiplas determinações. $\mathrm{O}$ estudo fundamentou-se nos pressupostos do Materialismo Histórico Dialético e da Pedagogia Histórico-Crítica como guia para as análises propostas. Ao final, os professores destacam a importância do planejamento nesta perspectiva, em que ao se apropriar da totalidade presente no conteúdo, o professor torna-se capaz de socializar o conhecimento como base no movimento dialético de prática-teoria-prática.

PALAVRAS-CHAVE: Pedagogia histórico-crítica. Planejamento. Formação humana.

RESUMEN: Este artículo tiene el objetivo de evidenciar un proceso formativo realizado con profesores de Lengua Portuguesa a la luz de la Pedagogía Histórico-Crítica. Se defiende una formación sólida que posibilite la apropiación del conocimiento en su totalidad, a fin de superar el inmediatismo y viabilizar la formación humana en sus múltiples determinaciones. El estudio se basó en los supuestos del Materialismo Histórico Dialéctico y de la Pedagogía Histórico-Crítica como guía para los análisis propuestos. Al final, los profesores destacan la importancia del planeamiento en esta perspectiva, en que, al apropiarse de la totalidad presente en el contenido, el profesor se vuelve capaz de socializar el conocimiento como base en el movimiento dialéctico de práctica-teoría-práctica.

PALABRAS CLAVE: Pedagogía histórico-crítica. Planificación. Formación humana

${ }^{1}$ Universidade Estadual de Londrina (UEL), Londrina - PR - Brasil. Doutoranda em Educação; Mestre em
Educação pelo Programa de Pós-Graduação em Educação da Universidade Estadual de Londrina. Professora
colaboradora da Universidade Estadual do Norte do Paraná. ORCID: http://orcid.org/0000-0002-8033-6561. E-
mail: geu_tc@ @otmail.com
${ }^{2}$ Universidade Estadual de Londrina (UEL), Londrina - PR - Brasil. Pós-doutora em Educação. Professora
adjunta do Departamento de Educação da Universidade Estadual de Londrina - UEL e professora do Programa
de Pós-Graduação em Educação. E-mail: sandrafranco26@ @otmail.com RIAEE - Revista Ibero-Americana de Estudos em Educação, Araraquara, v. 14, n. 4, p. 2141-2159, out./dez., 2019. e-ISSN: 1982-5587. DOI: https://doi.org/10.21723/riaee.v14i4.10408 
ABSTRACT: This article aims to evidence a training process conducted with teachers of Portuguese Language in the light of the Historical-Critical Pedagogy. It defends a solid education that allow the appropriation of knowledge in its entirety in order to overcome the immediacy and facilitate the human development in its multiple determinations. The present study was based on the assumptions of Dialectical Materialism History and HistoricalCritical Pedagogy as a guide for the proposed analyzes. At the end, the teachers emphasize the importance of planning in this perspective in which to appropriate all this content, the teacher is able to socialize knowledge as the basis of the dialectical movement of practicetheory-practice.

KEYWORDS: Historical-critical pedagogy. Planning. Human formation.

\section{Introdução}

O artigo busca evidenciar um processo formativo realizado à luz da Pedagogia Histórico-Crítica, por meio um grupo de estudos junto a dois professores de Língua Portuguesa de determinada Instituição Pública de ensino do Norte do Paraná. A instituição de ensino está vinculada ao projeto OBEDUC, que tem como objetivo articular a Educação Básica e o Ensino Superior, subsidiando ações compromissadas com a melhoria do processo de ensino e aprendizagem.

Tomada como dimensão da própria prática social, uma educação comprometida com o saber elaborado em sua totalidade busca, pelas esferas do saber, empreender "a crítica à educação burguesa evidenciando seus mecanismos e desmistificando sua justificação ideológica" (SAVIANI, 2009, p. 114), e ao mesmo tempo reorganizar o trabalho educativo, viabilizando o acesso ao conhecimento em suas múltiplas dimensões. Esta perspectiva de apreender a educação como prática social tem como contribuição teórica e metodológica o Materialismo Histórico-Dialético e a Pedagogia Histórico-Crítica.

A pesquisa apresenta-se como recorte de uma pesquisa de mestrado, a qual teve como objetivo investigar as possíveis práticas de leitura presentes na realidade de alunos e professores do $1^{\circ}$ ano do Ensino Médio e as possíveis mudanças obtidas após a realização de um grupo de estudos com os professores de Língua Portuguesa e suas intervenções em sala de aula.

Assim, o texto propõe uma breve reflexão sobre a influência da formação docente na concepção de mundo e nas possibilidades concretas em sala de aula. Em seguida, ao analisar o grupo de estudos busca-se evidenciar o próprio movimento do método em questão, destacando a Prática Social Inicial dos professores envolvidos, o momento da teoria, em que 
se problematizou a realidade social posta e o momento da catarse, em que os professores puderam demonstrar em uma síntese, ou seja, pela elaboração do planejamento de trabalho docente-discente, o quanto haviam se apropriado do método e da didática proposta.

\section{Metodologia do grupo de estudos}

Por meio de uma ação transformadora, o homem é capaz de questionar e compreender os determinantes econômicos, sociais e históricos, que permitem uma análise crítica da realidade e a efetivação da práxis, ou seja: "reflexão e ação sobre uma realidade buscando sua transformação; transformação orientada para a consecução de maiores níveis de liberdade do indivíduo e da humanidade em seu trajeto histórico (interesse crítico).” (GAMBOA, 2011, p. 9).

Das instituições participantes do Projeto OBEDUC, selecionamos uma instituição para a pesquisa, conforme o critério de conveniência (localização, horário das aulas, nível escolar) e as possibilidades de realização do trabalho proposto junto aos professores e alunos desta instituição. Dos professores participantes da pesquisa, ambos possuem licenciatura em Letras, sendo que o Professor A atua no colégio há cerca de dez anos e participa do projeto OBEDUC há cerca de um ano, e o professor B atua no colégio há quatro anos e não participa do projeto mencionado, mas aceitou colaborar com a pesquisa participando do Grupo de Estudos e das intervenções.

Para assegurar a participação dos sujeitos da pesquisa, realizamos primeiramente um contato inicial com os professores e a direção escolar para a coleta de declaração de concordância dos serviços envolvidos e/ou de instituição coparticipante, conforme as normas do Comitê de Ética de Pesquisa.

Após a aprovação pelo comitê de ética, propusemos aos professores o início do Grupo de Estudos com as fundamentações teórico-metodológicas que sustentam a Pedagogia Histórico-Crítica e suas contribuições para o ato de ler em sala de aula.

Assim, realizou-se o grupo de estudos, objetivando instrumentalizar os professores para a elaboração de um planejamento de trabalho docente-discente com o conteúdo leitura literária. Os estudos se fundamentaram no Materialismo Histórico-Dialético e na Pedagogia Histórico-Crítica, realizando leituras e análises sobre Marxismo, Educação e Leitura, Sociedade e Literatura. Ao longo do Grupo de Estudos, utilizamos o diário de bordo para anotações sobre as principais percepções dos professores acerca dos textos estudados e de sua prática pedagógica. 


\section{Pedagogia histórico-crítica: uma teoria dialética da educação}

O materialismo histórico e dialético em si não se constitui uma teoria pedagógica, no entanto, fornece categorias fundamentais para a compreensão da realidade social atual e seus desdobramentos na educação escolar. O movimento apreendido pelo método de análise da realidade social é o mesmo movimento preconizado por Saviani (2011) ao propor a Pedagogia Histórico-Crítica.

A tarefa de uma Pedagogia inspirada no Materialismo Histórico-Dialético implica para Saviani (2012) em uma concepção de mundo que apreende uma base ontológica, epistemológica e metodológica. Apropriando-se dessa concepção trataria de incorporar este conhecimento à realidade social, ou seja, reconstruir diretrizes que possibilitam a reorganização do trabalho educativo, finalidades e objetivos da educação e das instituições formadoras, dos conteúdos, procedimentos que darão início a um novo movimento de desenvolvimento educativo, objetivando uma nova sociedade e um novo homem.

Ao compreender a educação como o ato de produzir em cada indivíduo singular a humanidade que é produzida intencionalmente pelo conjunto dos homens, Saviani (2008; 2011) propõe a Pedagogia Histórico-Crítica, uma teoria da educação interessada em articular os conhecimentos escolares com as necessidades humanas da classe trabalhadora. Nas suas palavras "Essa defesa implica a prioridade de conteúdo. Os conteúdos são fundamentais e sem conteúdos relevantes, conteúdos significativos, a aprendizagem deixa de existir, ela transforma-se num arremedo, ela transforma-se numa farsa." (SAVIANI, 2008, p. 44-45). Para tanto, o autor complementa que “[...] o dominado não se liberta se ele não vier a dominar aquilo que os dominantes dominam. Então, dominar o que os dominantes dominam é condição de libertação.” (SAVIANI, 2008, p. 45).

Saviani (2008; 2012) esclarece, porém, que o método por ele preconizado não pressupõe a somatória de métodos tradicionais e métodos novos, pois ambos se desenvolvem independentes da situação social. Sua proposta está estritamente vinculada a um posicionamento frente à sociedade. A prática social se constitui como ponto de partida e de chegada da prática educativa.

Assim, o trabalho educativo realiza um processo de mediação que busca, por meio do conhecimento historicamente acumulado, possibilitar a superação de uma inserção acrítica para uma inserção crítica e intencional na prática social. Esta mediação docente torna-se efetiva nos momentos intermediários do método, que são a problematização que viabiliza a tomada de consciência dos principais problemas colocados frente à prática social, a 
instrumentalização, momento em que os alunos se apropriam dos instrumentos teóricos e práticos necessários para a compreensão e solução dos problemas levantados e a catarse, isto é, a incorporação dos elementos apropriados durante o trabalho pedagógico na própria vida dos alunos.

$\mathrm{O}$ ponto de chegada é o retorno à prática social. Torna-se perceptível uma transformação do sujeito frente à prática social, que se constituindo elemento objetivo e ativo na sociedade, transforma-se e propõe possibilidades de transformações na própria prática. (SAVIANI, 2008).

$\mathrm{Na}$ busca por orientar a ação docente para conduzir-se dialeticamente neste processo, encontramos em Gasparin (2012) uma proposta Didática para o planejamento do processo de ensino aprendizagem nesta perspectiva, a qual intitulou ser "Uma didática para a Pedagogia Histórico-Crítica”. Nas palavras de Saviani, esta obra apresenta-se como uma forma possível de traduzir os princípios da Pedagogia Histórico-Crítica, somando-se ao esforço comum empreendido na implementação prática desta teoria (GASPARIN, 2012), o que nas palavras de Gasparin se traduz em "[...] caminhar da realidade social, como um todo, para a especificidade teórica da sala de aula e desta para a totalidade social novamente, tornando-se possível um rico processo dialético de trabalho pedagógico" (GASPARIN, 2012, p. 3).

Assim, buscar possibilidades transformadoras para a educação pressupõe analisar a sociedade sob uma perspectiva crítica, sendo os estudos de Marx (2004; 2008a; 2008b; 2009) fundamentos pertinentes para compreendermos a situação atual do mundo capitalista e vislumbrarmos possibilidades de mudanças. Entendemos ainda que apropriar-se destas reflexões e incorporá-las à educação é um trabalho árduo, os quais estudiosos como Saviani (2008; 2011) e Gasparin (2012) têm se empenhado e apresentado contribuições valiosas.

\section{Prática social inicial: uma leitura da realidade}

Ao assumirmos a ação docente como objeto de análise nessa pesquisa, consideramos que não estamos nos referindo à prática de sujeitos isolados, mas à prática de homens que se desenvolvem e se confirmam num dado momento histórico, em um espaço contraditório entre o saber dominante e o saber dominado, em que a função de socializar o conhecimento historicamente acumulado pode estar respondendo a este ou aquele tipo de sociedade.

Ao propor uma formação para professores, "nos deparamos com uma tensão crucial: a contradição entre o dever ser da referida formação e as possibilidades concretas para sua efetivação.” (MARTINS; DUARTE, 2010, p. 14). Duarte $(2015$, p. 9) aponta que “[...] uma 
das características elucidadas pela Pedagogia Histórico-Crítica reside na relação entre o trabalho educativo e a formação/transformação da concepção de mundo de alunos e professores". O caminho deste processo refere-se à própria efetivação do trabalho educativo com a totalidade do conhecimento científico, artístico e filosófico "fundamentado na concepção de mundo materialista, histórica e dialética" (DUARTE, 2015, p. 15). A partir de uma base teórica consistente o professor é instrumentalizado para apropriar-se da riqueza produzida pela humanidade, considerando sua dimensão histórica, social, política, econômica, ideológica, psicológica, para que ao final do processo haja a compreensão do todo, sendo esta compreensão, a compreensão da própria realidade social.

Assim, tomamos como ponto de partida a prática social inicial dos professores participantes, a fim de apreender as percepções iniciais dos sujeitos da pesquisa. No diário de bordo da pesquisadora, podemos constatar algumas observações pertinentes no primeiro encontro com os professores:

O professor B aponta que está ansioso pelas discussões, que durante sua atuação enquanto docente neste colégio há 4 anos, nunca participou de um Grupo de Estudos no ambiente escolar que tratasse sobre suas ações em sala de aula. O professor relata que sempre que a Universidade propõe algo para ser desenvolvido no espaço escolar, os professores participam de uma forma mais indireta. Relata que normalmente os pesquisadores trazem o material pronto, como é para ser feito, sem discussões e reflexões teóricas com os docentes (DIÁRIO DE BORDO, 17 set. 2015).

Um dos grandes desafios da educação escolar contemporânea consiste na produção de sentidos, na formação docente-discente para além do imediatismo presente no cotidiano da sociedade capitalista. Neste sentido, utilizar da ação dos professores limitando-os a uma reprodução de um conteúdo sem que haja um aprofundamento consiste um esvaziamento dos conhecimentos científicos no processo de ensino e aprendizagem. Assim, defende-se a participação ativa dos docentes como sujeitos de pesquisa, que em seu trabalho educativo se desenvolvem e se transformam juntamente com o desenvolvimento da realidade social pesquisada, ou seja, sua prática pedagógica.

Assim, a pesquisa sinaliza a necessidade de uma formação teórica consistente, capaz de orientar e de se fazer refletir sobre a prática pedagógica como expressão da própria prática social, cujo papel consiste na socialização do saber sistematizado, socialização esta que só pode ser efetivada na medida em que, superando o senso comum, o professor busca formas adequadas para juntamente com os alunos atingir níveis mais elevados de consciência humana frente ao conhecimento historicamente elaborado. 
Ao tratar da apropriação do conhecimento humano, Abrantes e Martins (2007) exemplificam este processo com imagem de um mergulho. Um indivíduo imerso na realidade imediata, sem o apoio consistente do conteúdo que sintetiza a experiência histórica do ser humano, corre o risco de se afogar nas inúmeras informações caóticas, ou simplesmente realizar pequenos avanços à custa de muito se bater, como aquele que não foi ensinado a nadar e é atirado na água. Assim, torna-se inadmissível omitir no trabalho educativo uma sólida formação teórica ou deixá-la como fator de menor importância frente ao imediatismo pragmático vivenciado nos nossos tempos.

Dada a importância da participação direta dos sujeitos da pesquisa para a apropriação ativa do conhecimento, questionamos os professores sobre o seu conhecimento a respeito da Pedagogia Histórico-Crítica, sendo ela fundamentação norteadora dos documentos oficiais do Estado do Paraná e objeto de estudo deste grupo. Em um dos diários, a pesquisadora relata:

Os professores apontam que durante sua formação inicial (Letras) não tiveram contato com este conteúdo, apenas com os pressupostos gerais do Marxismo na disciplina de Filosofia. O professor A relata que por participar das reuniões do Programa OBEDUC durante este ano tem tido um contato maior com estas leituras, porém que ainda desconhece sua efetivação na prática (DIÁRIO DE BORDO, 29 set. 2015).

Neste relato podemos perceber a fragilidade da formação dos professores, tanto inicial como continuada, e o esvaziamento de fundamentos científicos no processo de formação dos professores para sua práxis educativa. Concordamos com Leontiev (1978, p. 267), ao afirmar que "[...] cada indivíduo aprende a ser um homem. O que a natureza lhe dá quando nasce não lhe basta para viver em sociedade". Neste processo, o homem torna-se homem por meio da formação, ou seja, instrumentalizado pelo conhecimento historicamente acumulado.

\section{Teoria: compreensão e análise da realidade investigada}

O conhecimento da realidade em uma perspectiva Histórico-Crítica se inicia pela prática social, a fim de superar sua aparência e compreendê-la em sua essência, o que possibilita uma prática consciente. Este movimento pressupõe um método de pesquisa, o Materialismo Histórico-Dialético como base para os estudos junto aos professores, em que o processo do conhecimento eleva-se do abstrato ao concreto, em outras palavras, da síncrese à síntese pela mediação da análise.

Este movimento apresenta uma “[...] orientação segura tanto para o processo de descoberta de novos conhecimentos (o método científico) como para o processo de 
transmissão-assimilação de conhecimentos (o método de ensino)" (SAVIANI, 2008, p. 59). Compreendido nestes pressupostos, o movimento do método pedagógico incorpora a mediação como possibilidade de conhecimento teórico da relação entre o sujeito e a realidade investigada.

Assim, o momento de teorização no grupo de pesquisa está interligado à prática inicial, porém é o momento de superação daquela para a apropriação do conhecimento científico. A problematização é o momento que se inicia o trabalho com o conteúdo sistematizado, o processo de busca, de investigação para solucionar as questões em estudo por meio de situações-problemas. Um momento de análise da prática e da teoria, em que a totalidade apresenta-se como resultado de múltiplos aspectos. Os conteúdos surgem das próprias necessidades sociais, questões que precisam ser superadas em uma dimensão global e concomitantemente respondem às questões do grupo. $\mathrm{O}$ conhecimento é um produto social que surge das necessidades históricas, econômicas, políticas, ideológicas, filosóficas, etc. (GASPARIN, 2012).

Os questionamentos estiveram presentes ao longo dos estudos e dos conteúdos, buscando abordá-los enquanto necessidades sociais vinculadas a dimensões históricas, políticas, culturais, que compõe a totalidade do conhecimento. A instrumentalização apresenta-se como momento de apropriação dos instrumentos teórico-práticos para apropriação do conhecimento enquanto produção social e histórica. Para esta etapa do processo dialético, propusemos estudos e fundamentações teóricas, partindo do método até chegar à prática vivenciada em sala de aula. Buscamos desenvolver ao longo dos textos possibilidades para que os professores pudessem perceber a importância dos conteúdos escolares (Leitura e Literatura) para a formação humana e como se organizar uma proposta de ensino com os fundamentos da Pedagogia Histórico-Crítica. Os professores participaram com discussões, análises e sínteses que iam sendo socializadas junto ao grupo ao longo do processo de formação. Podemos observar durante os estudos que os apontamentos dos professores demonstraram as diversas dimensões do conteúdo proposto:

Sobre o estudo do método, o PB comenta que o estudo de Marx vai se adequando conforme o contexto social e partindo da realidade material. "E por isso que vemos o quanto seus estudos estão atuais e ainda estão presentes na realidade atual, no capitalismo. Na educação, em minha prática tenho buscado levantar essa realidade do aluno e fazer este direcionamento para que o aluno tenha essa visão do todo. (PB)" (DIÁRIO DE BORDO, 20 out. 2015). 
Percebemos que com o processo de estudos, os professores começam a ter uma percepção do método e suas relações com sua prática pedagógica, compreendendo que sua prática está vinculada a uma dimensão conceitual, social, política, econômica e que este todo, possibilita compreender a educação enquanto um processo em constante desenvolvimento.

Durante os estudos do método, o PA sintetiza que para Marx o papel do sujeito é essencialmente ativo para apreender não a aparência ou forma do objeto, mas a essência do objeto como um processo. O sujeito deve ser capaz de mobilizar o máximo de conhecimentos, criticá-los e revisá-los para chegar num todo. O PA questiona a pesquisadora: "Este seria o movimento da dialética? Não o todo perfeito, mas um ponto que me possibilite chegar a novos conhecimentos. Não tem um final, é um processo ativo. Na sala de aula muitas vezes não conseguimos fazer esse movimento, mas saber disso é muito interessante para vermos de outra forma e deixarmos de sermos tão passivos e ter mais atitudes em sala de aula. A educação é um processo que não acaba, tem sempre uma contradição, uma superação necessária em nossa realidade.” (DIÁRIO DE BORDO, 20 out. 2015).

O estudo do método e do movimento explicitado por Marx (2008) na análise da economia política possibilitou aos professores perceber que assim como a análise da economia política consiste em elevar-se do abstrato ao concreto por meio dos determinantes constitutivos da realidade, no conteúdo escolar este movimento também ocorre, sendo necessário analisar o conhecimento em suas múltiplas determinações, no qual o trabalho educativo exerce uma função mediadora entre a vida cotidiana e as esferas não cotidianas.

O PA observa que as dimensões que Marx aponta para analisar a sociedade estão presentes também na Literatura, pois sua construção e desenvolvimento perpassa um contexto histórico, de poder, ou seja, ela é um reflexo da sociedade que acompanha o movimento e o processo de mudança do próprio homem. O PA destaca que as correntes literárias se produziram com o processo de produção e transformação do próprio homem, dos seus conflitos, contradições (DIÁRIO DE BORDO, 20 out. 2015).

As relações sociais para Marx (2009) estão intimamente ligadas às forças produtivas, são produtos históricos e transitórios. "O moinho manual supõe uma divisão distinta daquela requerida pelo moinho a vapor.” (MARX, 2009, p. 125). Desta forma, ao adquirir novas forças produtivas o homem transforma o seu modo de produção, e ao transformá-lo, transforma todas as suas relações sociais. Contextualizando o método com o conteúdo "Literatura" percebemos algumas apropriações dos professores:

Ao discutir sobre a Obra "Senhora", o PB relata que esta obra vincula-se a uma dimensão histórica, social, cultural, econômica. O PB analisa que as questões tratadas no livro encontram-se presentes nos dias de hoje, a literatura possibilita explicar as mudanças e o desenvolvimento histórico. O 
PA aponta que a dimensão social se apresenta muito forte na literatura, a influência dos valores da sociedade nas relações sociais presentes nas obras. Que não existe um livro que não te acrescente alguma coisa. A literatura faz com que construa mundos, significados. Porém afirma que na televisão está tudo pronto e os alunos estão acostumados com estas facilidades, então questiona: "Como fazer com que os alunos se interessem"? (DIÁRIO DE BORDO, 27 out. 2015).

No que tange ao questionamento do professor sobre o interesse do aluno ao seu processo de aprendizagem, compreendemos que o objetivo do trabalho educativo consiste no desenvolvimento do sujeito, logo, seus interesses devem ser levados em conta. Porém, devemos indagar: "De que aluno estamos falando? Do aluno empírico ou do aluno concreto?" (SAVIANI, 2015, p. 40). Com este questionamento, podemos compreender que o aluno empírico tem determinados desejos e aspirações que correspondem à sua situação empírica imediata vivenciada, sendo que nem sempre suas aspirações correspondem aos interesses necessários à formação de um sujeito concreto, que se desenvolve segundo condições sociais determinadas.

O trabalho educativo ao olhar para o sujeito concreto organiza-se de forma a desenvolver o sujeito histórico-social em uma relação dialética com o outro e com a produção humana. Assim, a partir de uma base teórica consistente o professor é instrumentalizado para apropriar-se da riqueza produzida pela humanidade e considerando sua dimensão histórica, social, política, econômica, ideológica, psicológica, entre outras, busca-se formas possíveis para a transmissão do saber elaborado e a formação do aluno concreto com interesses no âmbito social, cultural, econômico, político, entre outros.

Podemos sintetizar que o aprendizado cria sentidos por meio da apropriação do conhecimento, ou seja, pela incorporação das conquistas da humanidade, permitindo aos sujeitos vivenciar os momentos mais significativos da história humana. A definição dos conteúdos escolares é uma das questões fundamentais para o trabalho educativo. Ao defender o ensino e a aprendizagem dos clássicos, a Pedagogia Histórico-Crítica aponta ser este um caminho de possibilidades para a apropriação da experiência histórica humana. (DUARTE, 2015). A apropriação dos conhecimentos mais elaborados colabora ainda para a formação das funções psíquicas superiores e o desenvolvimento da consciência, que possibilita o desenvolvimento humano e a superação dos limites utilitaristas do alienante cotidiano da sociedade capitalista.

O clássico, nesse sentido, é aquilo que se consolidou como essencial para a continuidade do desenvolvimento humano. Na educação consiste na identificação dos 
elementos culturais que precisam ser assimilados, trata-se de distinguir entre o principal e o secundário. Assim, o processo de transmissão-assimilação do saber elaborado tem como referência aquilo que se firmou como clássico, e este pode se constituir num critério útil para delimitar os conteúdos imprescindíveis ao trabalho educativo (SAVIANI, 2011).

Neste sentido, encontramos na arte e em suas diversas manifestações possibilidades efetivas de produzir a humanidade elaborada historicamente e recuperar os sentidos humanos alienados pela sociedade capitalista. Fruto da história da humanidade, a arte reúne representações subjetivas que traduzem a realidade concreta elaborada ao longo do desenvolvimento histórico.

Independente de se situar no campo das artes, ciências ou filosofia, a eficácia dos clássicos no âmbito educativo é determinada tanto pela riqueza de seu conteúdo quanto pelo seu significado em determinado momento para o desenvolvimento da individualidade do aluno, tornando-se imprescindível a mediação, por parte do professor, entre o conteúdo a ser ensinado e a forma pela qual ele será ensinado (DUARTE, 2015). Assim, um ensino intencionalmente organizado possibilita por meio de formas adequadas que a relação entre conteúdo e forma de uma obra literária, por exemplo, chegue ao aluno pela mediação de uma forma didática e de um conteúdo objetivado para o conhecimento humano.

\section{Catarse: o planejamento de trabalho docente-discente na perspectiva histórico- crítica}

Esta unidade possibilitou aos professores expressar a categoria catártica do processo formativo, a síntese do conhecimento apropriado ao longo do processo. A catarse, para a Pedagogia Histórico-Crítica, só é possível pelo movimento da síncrese à síntese, o que expressa uma nova forma de entender a prática inicial. Neste momento, evidencia-se que a realidade conhecida como natural não é exatamente desta forma, mas é histórica, social, política, produzida pelos homens em determinado tempo e lugar a fim de atender as necessidades socioeconômicas situadas desses mesmos homens (GASPARIN, 2012).

Neste sentido, a expressão elaborada dessa nova síntese se deu por meio da elaboração de um planejamento de trabalho docente-discente na perspectiva Histórico-Crítica. A escolha pela Didática preconizada por Gasparin (2012) refere-se às suas possibilidades de traduzir os princípios da Pedagogia Histórico-Crítica para o trabalho educativo em sala de aula. 
Quadro 1 - Projeto de trabalho docente-discente na perspectiva histórico-crítica

\begin{tabular}{|c|c|c|c|c|}
\hline \multicolumn{5}{|c|}{ Instituição:_ Professor (a): } \\
\hline \multicolumn{5}{|c|}{ Disciplina: $\_$Unidade: } \\
\hline Ano Letivo: & Bimestre: & Série/ano: & Turma: & $\mathrm{H} / \mathrm{a}$ \\
\hline $\begin{array}{l}\text { PRÁTICA } \\
\text { Nível de } \\
\text { desenvolvimento } \\
\text { atual }\end{array}$ & Zon & $\begin{array}{c}\text { TEORIA } \\
\text { Desenvolvimento im }\end{array}$ & iato & $\begin{array}{c}\text { PRÁTICA } \\
\text { Novo nível de } \\
\text { desenvolvimento } \\
\text { atual }\end{array}$ \\
\hline $\begin{array}{l}\text { Prática Social } \\
\text { Inicial do Conteúdo }\end{array}$ & Problematização & Instrumentalização & Catarse & $\begin{array}{l}\text { Prática Social } \\
\text { Final do Conteúdo }\end{array}$ \\
\hline $\begin{array}{l}\text { 1) Listagem do } \\
\text { conteúdo } \\
\text { objetivos: Unidade: } \\
\text { objetivo geral } \\
\text { Tópicos: objetivos } \\
\text { específicos }\end{array}$ & $\begin{array}{l}\text { 1) Identificação e } \\
\text { discussão sobre os } \\
\text { principais } \\
\text { problemas postos } \\
\text { pela prática social e } \\
\text { pelo conteúdo. }\end{array}$ & 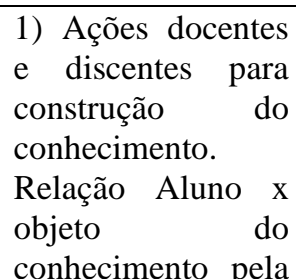 & $\begin{array}{l}\text { 1) Elaboração } \\
\text { teórica da } \\
\text { síntese, da nova } \\
\text { postura mental. } \\
\text { Construção da } \\
\text { nova totalidade } \\
\text { concreta. }\end{array}$ & $\begin{array}{l}\text { 1) Intenções do } \\
\text { aluno. } \\
\text { Manifestação da } \\
\text { nova postura } \\
\text { prática, da nova } \\
\text { atitude sobre o } \\
\text { conteúdo e da nova }\end{array}$ \\
\hline $\begin{array}{l}\text { 2) Vivência } \\
\text { cotidiana do } \\
\text { conteúdo: } \\
\text { a) O que o aluno já } \\
\text { sabe: visão da } \\
\text { totalidade empírica. } \\
\text { Mobilização. } \\
\text { b) Desafio: o que } \\
\text { gostaria de saber a } \\
\text { mais? }\end{array}$ & $\begin{array}{l}\text { 2) Dimensões do } \\
\text { conteúdo a serem } \\
\text { trabalhadas. }\end{array}$ & $\begin{array}{lr}\text { mediação docente. } \\
\text { 2) } \\
\text { humanos } \\
\text { materiais. }\end{array}$ & $\begin{array}{l}\text { 2) Expressão } \\
\text { prática } \\
\text { síntese. } \\
\text { Avaliação: deve } \\
\text { atender } \\
\begin{array}{l}\text { dimensões } \\
\text { trabalhadas e aos } \\
\text { objetivos. }\end{array} \\
\end{array}$ & $\begin{array}{l}\text { forma de agir. } \\
\text { 2) Ações do aluno. } \\
\text { Nova prática social } \\
\text { do conteúdo, em } \\
\text { função } \\
\text { transformação } \\
\text { social. }\end{array}$ \\
\hline
\end{tabular}

Fonte: Gasparin (2012, p. 159)

Tendo como parâmetro o quadro apresentado, observamos que a educação passa a ser compreendida como mediação da prática social global. A prática social se põe tanto como ponto de partida como também ponto de chegada do processo educativo, decorrendo assim um método pedagógico, em que professor e aluno se encontram igualmente inseridos, ocupando, porém, posições distintas (prática social inicial), condição para que levantem os problemas postos pela prática social em diferentes dimensões (problematização), e por meio de instrumentos teóricos e práticos para sua compreensão e solução (instrumentação), viabiliza-se a incorporação do conhecimento científico como elemento integrante da própria vida do aluno (catarse). Assim, o conhecimento retorna à prática da qual partiu, visando agir sobre ela de forma consciente (prática social final) (GASPARIN, 2012; SAVIANI, 2008).

Com as observações anteriores, podemos referir ao que Duarte $(2015$, p.18) chama de “adequada articulação, por parte do professor, entre o conteúdo a ser ensinado e a forma pela qual ele será ensinado". Neste sentido, a forma proposta por esta Didática da Pedagogia Histórico-Crítica é aquela capaz de unir-se ao conteúdo, estabelecer uma relação entre o 
cotidiano e o não cotidiano, valorizando as experiências de cada aluno, mas sem perder de vista as experiências acumuladas pela humanidade. Os resultados obtidos com essa forma didática de trabalho docente-discente apresentam-se como possibilidades para a apropriação do conhecimento significativo e como instrumento de formação humana.

Com a fundamentação proposta, os professores puderam elaborar um planejamento de trabalho docente-discente a ser desenvolvido em sala de aula, a partir do tema "Leitura Literária", considerando a literatura como conteúdo clássico e pertinente para o desenvolvimento humano. Durante a elaboração do projeto tornou-se perceptível o envolvimento ativo dos docentes, na seleção de conteúdos e instrumentos, operações e ações de que possibilitassem a aprendizagem e desenvolvimento dos alunos na elaboração de sentidos e significados frente ao ato de ler.

Os professores apontam que não conheciam esta forma de planejamento conforme a Didática proposta por Gasparin (2012). A pesquisadora retoma alguns aspectos principais que devem estar presentes no planejamento e juntos iniciam sua elaboração. O professor A aponta a necessidade de contextualizar o título do conto escolhido, o "Holocausto" com o período histórico retratado no texto, discutindo com os alunos o holocausto da sociedade atual, o sacrifício e a desumanização do homem frente à sua realidade e o sacrifício diário no tráfico, na violência. O professor $\mathrm{B}$ complementa que diariamente vive-se um holocausto em vida. O professor $\mathrm{A}$ afirma a necessidade de o aluno perceber que este holocausto ainda está presente na vida atual, aponta a necessidade de partir do global e chegar à cotidianidade do aluno. E neste sentido, os professores elaboram os objetivos, problemas, instrumentos. O professor A relata que tem buscado trabalhar com as sensações em sala de aula e que seria interessante inserir uma música no planejamento. "Eles leem o texto primeiro e depois podem ouvir a música" (PA). Segundo o professor, seria uma oportunidade dos alunos conhecerem uma letra de música mais elaborada, com sentido social. (DIÁRIO DE BORDO, 17 nov. 2015).

Neste sentido, uma abordagem marxista da leitura, sugere pensar que promover o contato com os conteúdos clássicos mais representativos do gênero humano pressupõe entrar em contato com o patrimônio literário de mais alto grau de elaboração humana. Inserida no patrimônio artístico da humanidade está a literatura, que, sendo um valiosíssimo legado cultural, necessita ser socializada e acessada pelas vias da educação escolar. A literatura possibilita desenvolver no homem uma consciência de gênero humano, e ao mesmo tempo, contraditoriamente, entender o que na história há de mais desumano (DUARTE, 2015; FERREIRA; DUARTE, 2010).

Como expressão da práxis pedagógica, o ato de ler se constitui como possibilidade de desenvolvimento e humanização do sujeito, pressupõe a apropriação da totalidade presente no 
texto, um processo que perpassa a decodificação das letras para a reflexão e ação do leitor, conforme demonstrado no planejamento elaborado juntamente com os professores.

Quadro 2 - Planejamento de trabalho docente-discente elaborado pelos professores

\section{PLANO DE UNIDADE}

Disciplina: Língua Portuguesa

Unidade de conteúdo: Literatura: $\mathrm{O}$ ato de ler contos e suas possibilidades para uma leitura histórico-social. Ano Letivo: 2015. Bimestre: $4^{\circ}$ Série: $1^{\circ}$ Ano Ensino Médio Horas-aula da unidade: 6

\section{1 - PRÁTICA SOCIAL INICIAL DO CONTEÚDO}

1.1- Título da Unidade de Conteúdo: Literatura: $\mathrm{O}$ ato de ler contos e suas possibilidades para uma leitura histórico-social.

\section{Objetivo geral:}

Compreender a literatura como um produto social e humano que exprime condições históricas que possibilitam uma leitura e (re) leitura crítica da realidade, produzindo sentidos e interpretações ao sujeito leitor sobre sua realidade histórico-social.

Tópicos do conteúdo e objetivos específicos:

Tópico 1: Leitura e visão de mundo

Objetivo específico: Refletir sobre a leitura e suas sensações (Música/Áudio Cálice), afim de compreendê-la como uma prática social que possibilita discutir questões da experiência humana e analisar a realidade em suas múltiplas dimensões.

Tópico 2: Literatura e Contos

Objetivo específico: Compreender a importância dos contos e identificá-lo como gênero literário que demonstra intencionalidades e sentidos nos contextos históricos retratados, que podem ser reelaborados pelo leitor para a compreensão do contexto atual.

Tópico 3: Conto: "O Holocausto" de Caio Fernando de Abreu

Objetivo específico: Analisar o conto e o contexto de sua produção, no intuito de perceber as dimensões: conceitual, histórica, social, cultural, política, legal, afetiva, psicológica, estética, entre outras, que estão postas na leitura e na sociedade.

\section{2 - Vivência do conteúdo}

O que os alunos já sabem sobre o conteúdo a ser ministrado?

Literatura é ler livros clássicos, inclusive contos. Os contos também fazem parte da literatura. Os contos selecionados retratam situações de sofrimento e dor.

O que gostariam de saber a mais sobre o conteúdo?

O que é holocausto? Por que ao final do conto o personagem deseja a morte ao invés da vida? O que autor quis dizer com a expressão "trocar os piolhos" e "animais sangrentos das nossas bocas"? Qual foi objetivo do autor ao escrever este conto?

\section{2- PROBLEMETIZAÇÃ̃O}

2.1 - Discussões (elaborar algumas perguntas sobre o tema da aula para debate)

Qual a importância da leitura para compreendermos a sociedade? Qual a importância dos contos na Literatura? Quem foi o autor do conto apresentado? Em que época foi publicado? Quais os principais acontecimentos deste período histórico? Por que o autor escolheu retratar este período? A quem se dirigia tal obra? O que representou este texto nesta época? Como era a sociedade dessa época? Quais as sensações e percepções você experimentou ao sentir o objeto apresentado na "caixa de sensações" e como estas estão relacionados com o conto? As sensações sentidas são as mesmas antes e após a leitura do conto? Em qual contexto histórico você encaixaria 
este conto? Você já se colocou no lugar do outro em alguma situação? O sofrimento retratado no conto nos possibilita refletir sobre o sofrimento existe na nossa sociedade?

\section{2 - Dimensões do conteúdo a serem trabalhadas na Instrumentalização}

Conceitual/Científica: O que é Literatura? O que são contos? O que é holocausto?

Histórica: Qual a importância da literatura ao longo da história? Qual o contexto histórico que o conto está inserido?

Econômica: Por que a literatura não é tão comercializada nos dias de hoje?

Social: Como o holocausto vivenciado pelos personagens encontra-se presente na sociedade atual?

Cultural: Qual era a cultura vivenciada durante o contexto o qual foi elaborado o conto?

Ideológica: Por que muitos textos literários foram impedidos de circular durante o período ditatorial?

De Poder: Nos dias atuais ainda encontramos as mesmas relações de poder retratadas na obra?

Política: Qual a estrutura política retratada nos contos e suas semelhanças com a realidade social?

Doutrinária: Qual a doutrina imposta neste contexto histórico?

Afetiva/ Psicológica: Como o conto retrata o medo e a insegurança, vivenciado pelos personagens? No contexto vivenciado pelos personagens, quais os sentimentos que se faziam presentes?

Estética: De que forma o corpo é utilizado no conto para causar a sensação do grotesco?

Ética: Quais os comportamentos demonstrados nos personagens no conto? Seria ético lançar-se à morte?

Religiosa: Em qual dos três momentos históricos (2 $2^{\mathrm{a}}$ Guerra Mundial), (Hebreus), (Ditadura Militar) vocês acreditam que se referia o Holocausto do conto apresentado?

Prática: Como o conto e as reflexões realizadas podem contribuir para a compreensão de sua realidade?

\section{3- INSTRUMENTALIZAÇÃO}

3.1- Listar todas as técnicas, dinâmicas, processos, métodos que serão utilizados para apresentar o conteúdo científico nas dimensões indicadas anteriormente:

Tópico 1: Leitura e visão de Mundo

Cada aluno receberá a letra da música "Cálice" de Chico Buarque, onde será realizada a leitura silenciosa e em seguida irão ouvir a música com os olhos vendados. Os alunos poderão perceber e retratar as sensações que são despertadas ao ler e ouvir a música, demonstrando sua prática inicial.

Por meio da exposição oral, o professor irá realizar uma breve contextualização acerca do Regime Militar relacionando a fatos marcantes na carreira de Chico Buarque, em razão da perseguição por parte dos censores que proibiram a execução de grande parte de suas canções. Sua obra retrata a realidade do Brasil em vários aspectos, como revolta e insatisfação com as atitudes do governo militar. Por meio da música "cálice" pretendese inserir os alunos no momento histórico do conto literário selecionado, e, a partir deste, instigar os alunos a relacionar os acontecimentos presentes na obra literária que permanecem na sociedade atual.

Tópico 2: Literatura e contos

Aula dialogada e explicação: Apresentar o conceito de conto literário, suas características e particularidades em relação a outros gêneros textuais, como o gênero romance.

Tópico 3: Conto "O Holocausto"

Os alunos realizarão a leitura silenciosa do conto e por meio da problematização proposta será realizada uma aula dialogada, discussão e análise do conto e do contexto histórico-social de sua produção. Conceituação do termo Holocausto, seu caráter histórico-social e análise de algumas expressões presentes no texto.

3.2 - Listar os recursos necessários para a aula:

Textos, música, caixa, TV, pendrive, áudio.

\section{4- CATARSE}

4.1 - Síntese mental do aluno (no planejamento, colocar-se no lugar do aluno e fazer a síntese em seu lugar):

Ao ler, estamos relacionando dimensões sociais, culturais, políticas, econômicas, que possibilitam a compreensão do que se lê e a elaboração de sentidos sociais e individuais.

A literatura possibilita uma maior capacidade de linguagem, de interpretação e de reflexão crítica. Os contos são gêneros literários carregados de sentidos, pensamentos, ideologias que retratam um determinado tempo, espaço, cultura. 
O conto "Holocausto" possibilitou compreender o contexto vivenciado na Ditadura Militar, onde estão presentes várias dimensões. As dimensões estudadas auxiliam na compreensão da sociedade e da realidade atual. A análise crítica das informações contribui para a formação do sujeito social e para a mediação dos conflitos, levando a uma transformação de sua realidade e do próprio sujeito.

4.2 - Avaliações (tanto por perguntas quanto dissertação, considerar as dimensões vistas):

Se você tivesse que escrever um conto, retratando um problema social, sobre o que escreveria? Desenvolva um conto que retrate um problema, como o apresentado no conto holocausto, utilizando as dimensões trabalhadas e relacionando com as angústias atuais.

\section{5- PRÀTICA SOCIAL FINAL DO CONTEÚDO}

\section{Intenções do aluno}

Desejo compreender melhor como as relações sociais são retratadas a partir do estudo dos textos literários e como esta análise pode contribuir para a compreensão da realidade social.

\section{Ações do aluno}

Leituras e pesquisas sobre os contextos históricos, sociais, políticos, econômicos que estão presentes na literatura.

Manifestar meu ponto de vista sobre os acontecimentos deste período histórico e perceber suas influências na realidade social vivenciada.

Perceber como as obras literárias revelam intencionalidades que contribuem para a análise da sociedade atual.

\section{Referência}

GASPARIN, João Luiz. Esquema do Projeto de Trabalho docente-discente na perspectiva Histórico-Crítica. In: Uma didática para a Pedagogia Histórico-Crítica. 4.ed. Campinas: Autores Associados, 2012. p. 188-190.

Fonte: Elaboração própria.

Ao final da elaboração do planejamento os professores apontaram as contribuições desta metodologia:

Os professores relatam que durante o planejamento perceberam a necessidade de dominar o conhecimento em suas diversas áreas do saber. $\mathrm{O}$ professor A afirmou que neste processo o que achou mais interessante é a possibilidade de ver cada fase do processo sendo efetivada, o que faz também repensar sobre sua ação em sala de aula. Sobre esta proposta voltada para a leitura, o professor B afirma que pretende realizar novas leituras e continuar planejando nesta perspectiva, pois o aluno é capaz de se identificar com o texto, estabelecer relações entre o real e o fictício. (DIÁRIO DE BORDO, 17 nov. 2015).

De acordo com o trabalho desenvolvido, os professores puderam representar a efetivação de sua catarse frente ao conteúdo trabalhado, ou seja, a sistematização e manifestação dos conteúdos apreendidos durante o processo em uma nova totalidade social. O conteúdo passa a se constituir como elemento de luta para a compreensão e transformação social. Dessa forma, tornou-se possível aos professores compreender a importância de identificar os elementos culturais necessários (no caso, a literatura) que precisam ser assimilados para que os indivíduos se apropriem da humanidade que é produzida 
historicamente e, assim, também a necessidade de apresentar formas adequadas para atingir este objetivo, conforme estabelecido no planejamento didático.

Os professores puderam perceber que planejar nesta perspectiva pressupõe a apropriação de instrumentos teórico-práticos que estejam fundamentados em uma visão crítico-dialética, em que o professor ao se apropriar da totalidade presente no conteúdo, tornase capaz de socializar o conhecimento como base no movimento dialético de prática-teoriaprática.

No Grupo de Estudos, a Prática Social Final indicou a manifestação de uma nova postura frente ao conteúdo trabalhado por meio de uma ação consciente, que pode ser observada no planejamento de trabalho dos professores e na efetiva aplicação do planejamento junto aos alunos.

\section{Considerações finais}

Ao socializar o saber e viabilizar sua apropriação pelos homens, a educação escolar possibilita a formação humana, considerando que somente por meio do domínio do conhecimento elaborado pela humanidade é que os homens podem desenvolver-se conscientemente frente à sua realidade social.

No intuito de romper a dicotomia teoria versus prática, durante o Grupo de Estudos os professores puderam perceber que o trabalho pedagógico constitui-se de uma dimensão da realidade social global e a compreensão desta totalidade em suas múltiplas determinações é o que possibilita compreender e transformar sua prática pedagógica.

Podemos considerar que mesmo com as limitações da intervenção, o movimento realizado possibilitou aos professores um enriquecimento da sua visão de mundo. A partir do método dialético, os professores experimentaram uma nova forma didática de se propor o conhecimento, e por meio desta forma apropriada primeiramente pelos professores, os alunos puderam experimentar na leitura literária tempos e espaços estranhos a eles, mas que mesmo contraditórios apresentam-se vinculados à sua realidade social. Somadas às suas experiências, o conhecimento tanto do método para os professores, como da leitura literária para os alunos, faz-se a ultrapassar as impressões imediatas e desenvolve uma nova percepção, que pode ser objetivada por ambos na sua concepção de mundo e no ato de ler (FERNANDES, 2017).

Entendemos que o trabalho realizado buscou apresentar uma nova possibilidade de conduzir o trabalho educativo, porém a apropriação da totalidade é um processo em constante desenvolvimento. Apropriar-se de uma concepção de mundo materialista histórica e dialética 
que possibilita vislumbrar o conhecimento em todas as suas dimensões pressupõe a difusão desta concepção de mundo ao longo do processo de escolarização.

\section{REFERÊNCIAS}

ABRANTES, A. A.; MARTINS, L. M. A produção do conhecimento científico: relação sujeito-objeto e desenvolvimento do pensamento. Interface, Botucatu, v. 11, n. 22, p. 313325. maio/ago. 2007. Disponível em: http://www.scielo.br/pdf/icse/v11n22/10.pdf. Acesso em: 12 jun. 2016.

DUARTE, N. A importância da concepção de mundo para a educação escolar: porque a Pedagogia Histórico-Crítica não endossa o silêncio de Wittgenstein. Germinal: Marxismo e Educação em Debate, Salvador, v. 7, n. 1, p. 8-25, jun. 2015. Disponível em: http://www.portalseer.ufba.br/index.php/revistagerminal/article/view/12808. Acesso em: 20 dez. 2015.

FERNANDES, G. F. G. A ação docente: possibilidades do ato de ler na Educação Básica. 2017. 166fls. Dissertação (Mestrado em Educação) - Universidade Estadual de Londrina, Londrina, 2017.

FERREIRA, N. B. de P.; DUARTE, N. Literatura e Educação: Uma análise marxista. Cadernos de Campo, Araraquara, v. 1, n. 13, p.125-136, 2010. Disponível em: http://seer.fclar.unesp.br/cadernos/article/view/5141/4216. Acesso em: 04 jul. 2016.

GAMBOA, S. S. Os projetos de pesquisa: alguns fundamentos lógicos necessários. In: BRYAN, N.; MIRANDA, E. (Editores). (Re) pensarlaeducación pública: aportes desde Argentina y Brasil, Córdoba: Ed Universidad Nacional de Córdoba, 2011.

GASPARIN, J. L. Uma didática para a pedagogia histórico-crítica. Campinas: Autores Associados, 2012.

LEONTIEV, A. O desenvolvimento do psiquismo. Lisboa: Livros Horizonte, 1978.

MARTINS. L.; DUARTE; N. Formação de professores: limites contemporâneos e alternativas necessárias. São Paulo: Cultura acadêmica, 2010.

MARX, K. Manuscritos econômico-filosóficos. Tradução de Jesus Ranieri. São Paulo: Boitempo Editorial, 2004.

MARX, K. Contribuição à Crítica da Economia Política. Tradução e Introdução de Florestan Fernandes. 2. ed. São Paulo: Expressão Popular, 2008a.

MARX. K. Manifesto do partido comunista. São Paulo: Expressão Popular, 2008b.

MARX, K. Miséria da Filosofia. São Paulo: Expressão Popular, 2009.

SAVIANI, D. Escola e democracia. (Coleção educação contemporânea). Campinas: Autores Associados, 2008. 
SAVIANI, D. Modo de produção e a Pedagogia Histórico-Crítica. Germinal: Marxismo e Educação em Debate, Londrina, v. 1, n. 1, p. 110-116, jun. 2009. Disponível em: http://www.portalseer.ufba.br/index.php/revistagerminal/article/viewFile/9844/7129. Acesso em: 10 nov. 2015.

SAVIANI, D. Pedagogia histórico-crítica: primeiras aproximações. 11. ed. Campinas: Autores Associados, 2011.

SAVIANI, D. Origem e desenvolvimento da pedagogia histórico-crítica. In: COLÓQUIO INTERNACIONAL MARX E ENGELS - "Marxismo e Educação: Fundamentos Marxistas da Pedagogia Histórico-Crítica", 7, 2012, Campinas. Anais Eletrônicos... Campinas: IFCHUNICAMP, 2012. Mesa Redonda. Disponível em:

http://www.ifch.unicamp.br/formulario_cemarx/selecao/2012/trabalhos/Demerval\%20Saviani .pdf. Acesso em: 4 ago. 2015.

SAVIANI, D. O conceito dialético de mediação na pedagogia histórico-crítica em intermediação com a psicologia histórico-cultural. Germinal: Marxismo e Educação em Debate, Salvador, v. 7, n. 1, p. 26-43, jun. 2015. Disponível em: http://www.portalseer.ufba.br/index.php/revistagerminal/article/view/13575/951. Acesso em: 20 dez. 2015.

\section{Como citar este artigo:}

FERNANDES, Geuciane Felipe Guerim; FRANCO, Sandra Aparecida Pires. Reflexão e ação: a pedagogia histórico-crítica e suas possiblidades em grupo de estudo com professores de Língua Portuguesa. Revista Ibero-Americana de Estudos em Educação, Araraquara, v. 14 , n. 4, p. 2141-2159, out./dez., $2019 . \quad$ e-ISSN: 1982-5587. DOI: https://doi.org/10.21723/riaee.v14i4.10408

Data de Submissão: 18/09/2017

Revisões requeridas: 13/11/2017

Aceite em: 15/06/2018

Publicado em: 02/09/2019 